(REVIEW ARTICLE)

\title{
Bruxism in children, is it a result of psychological problems?
}

\author{
Rahhal Ahmad ${ }^{1,}{ }^{*}$, Ahmead Muna ${ }^{2}$, Jaradat Mohammed ${ }^{1}$ and Issa Haytham ${ }^{3}$ \\ ${ }^{1}$ Faculty of Dentistry Department of Orthodontics, Arab American University, Palestine. \\ ${ }^{2}$ Faculty of Public Health, Alquds University, Palestine. \\ ${ }^{3}$ Faculty of Dentistry Department of Oral and Maxillofacial Surgery, Arab American University, Palestine.
}

Publication history: Received on 05 July 2020; revised on 20 July 2020; accepted on 24 July 2020

Article DOI: https://doi.org/10.30574/wjarr.2020.7.1.0244

\begin{abstract}
Bruxism is involuntary, excessive grinding, clenching or rubbing of teeth during non-functional movements of the mastication. it is a destructive habit that may result in tooth wear. Although research on bruxism is extensive, its etiology remains debatable. The literature suggests that bruxism is correlated with both experienced and anticipated life stress. The purpose of this article is to review describe 3 out of 8 cases of severe bruxism in children of similar age with different life histories and to discuss the factors that could have triggered this parafunctional condition..
\end{abstract}

Keywords: Bruxism; Psychological problems; Bite plate

\section{Introduction}

Bruxism is involuntary, excessive grinding, clenching or rubbing of teeth during non-functional movements of the mastication $[1,2,3]$. Reported prevalence in children ranges from $7 \%$ to $15.1 \%[4,5,6]$ with girls apparently more frequently affected [7]. Bruxism can occur during the day or night [8]. Generally, patients clench their teeth throughout the day, gnash, and clench them during sleep [9]. However, nocturnal bruxism is more frequent; it varies with the individual and has been related to emotional or physical stress. [10] Bruxism cannot be considered normal, even during the primary or mixed dentition stages. [11] However, it is not considered a pathology during childhood until structural damage of the stomatognathic system (muscles, teeth, mucosa and TMJ) is seen, [1] although harmful effects on parafunction have been described in the permanent dentition when bruxism develops early [12]. Bruxism usually causes tooth wear as evidenced by wear facets that can range from mild to severe and can be localized or found throughout the dentition. Other trauma to the dentition and supporting tissues include thermal hypersensitivity, tooth hypermobility, injury to the periodontal ligament and periodontium, hypercementosis, fractured cusps, pulpitis and pulpal necrosis. [3] The etiology of bruxism has been defined as multifactorial. [13] It is mainly regulated centrally, not peripherally. [14] This means that oral habits, [15] temporomandibular disorders (TMD), [16-19] malocclusions, [20, 21] hypopnea, [22, 23] high anxiety levels [24] and stress [25, 26] among others [27] could influence the peripheral occurrence of bruxism. These factors act as motion stimuli to the central nervous system, which reacts with an alteration in the neurotransmission of dopamine, [28-30] and the result is the clenching or grinding of the teeth. The association between bruxism and TMD in children is strongly supported, [31-33] and the existence of an association between TMD and anxiety, depression and stress has been examined previously [34]. However, none of these studies demonstrated the causality of the relation between the psychological factors and TMD [35,36]. Alert parents ask dentists and physicians about tooth grinding of their children as well as the side effects of it and how to stop this habit. They often want to know the reason of this habit and its prevalence. Thus, it is important for dentists and physicians to inform parents properly [37].

A rigid occlusal splint (biteplate) is the most common form of treatment for bruxism. The aim of a biteplate is to stabilize and improve the function of the temporomandibular joint and muscles of mastication, diminish abnormal muscle activity and protect the teeth from excessive friction and traumatic loads [38]. Moreover, a biteplate can be used to

\footnotetext{
* Corresponding author: Rahhal Ahmad
} 
promote a stable, functional joint position and ideal occlusion, which, in turn, reorganizes neuromuscular activity, reducing in abnormal activity [39]. A review article reported that there is no effective treatment with permanent effect [40].Therefore, palliative approaches are recommended at present. It is expected that self-management of bruxism through self-relaxation reduces the frequency and intensity of awake bruxism. Occlusal adjustment of dentition and interocclusal appliances may be effective [40]. Although others reported that there is not sufficient evidence to state that the appliance is effective [41]. Regarding using medications in the treatment of bruxism, Propranolol is not effective [42]. Botulinum toxin injection may be effective $[43,44]$. Bromocriptine does not increase or decrease sleep bruxism [45]. Clonazepam decreases sleep bruxism [46, 47]. When considering the terminal planes, MS was present in $17.3 \%$ of the sample, DS in $10.5 \%$ and VP in $72.3 \%$ [48].

\section{Case Description}

In this report, we describe 3 cases of severe bruxism in children with different life histories and discuss the possible factors that could have triggered this parafunctional condition.

\subsection{Case 1}

A 6-year-old girl was brought to the orthodontic clinic by her mother. On history, her mother's chief complaint was that the girl's gnashing her teeth at night, and the severe wearing in her teeth since about one year. The child did not have any medical history. No previous dental treatment was reported. Ingestion of acid drinks or medication was denied. Although the mother described the child as highly excitable, during the consultation she was extremely shy and introspective. Her mother reported that the child had a bad experience a year ago, when she was coming back from the kindergarten the bus left her in front of her house but there was nobody at home, the mother was at the mall, and the girl was left there alone for 2 hours, with some dogs in the neighborhood.
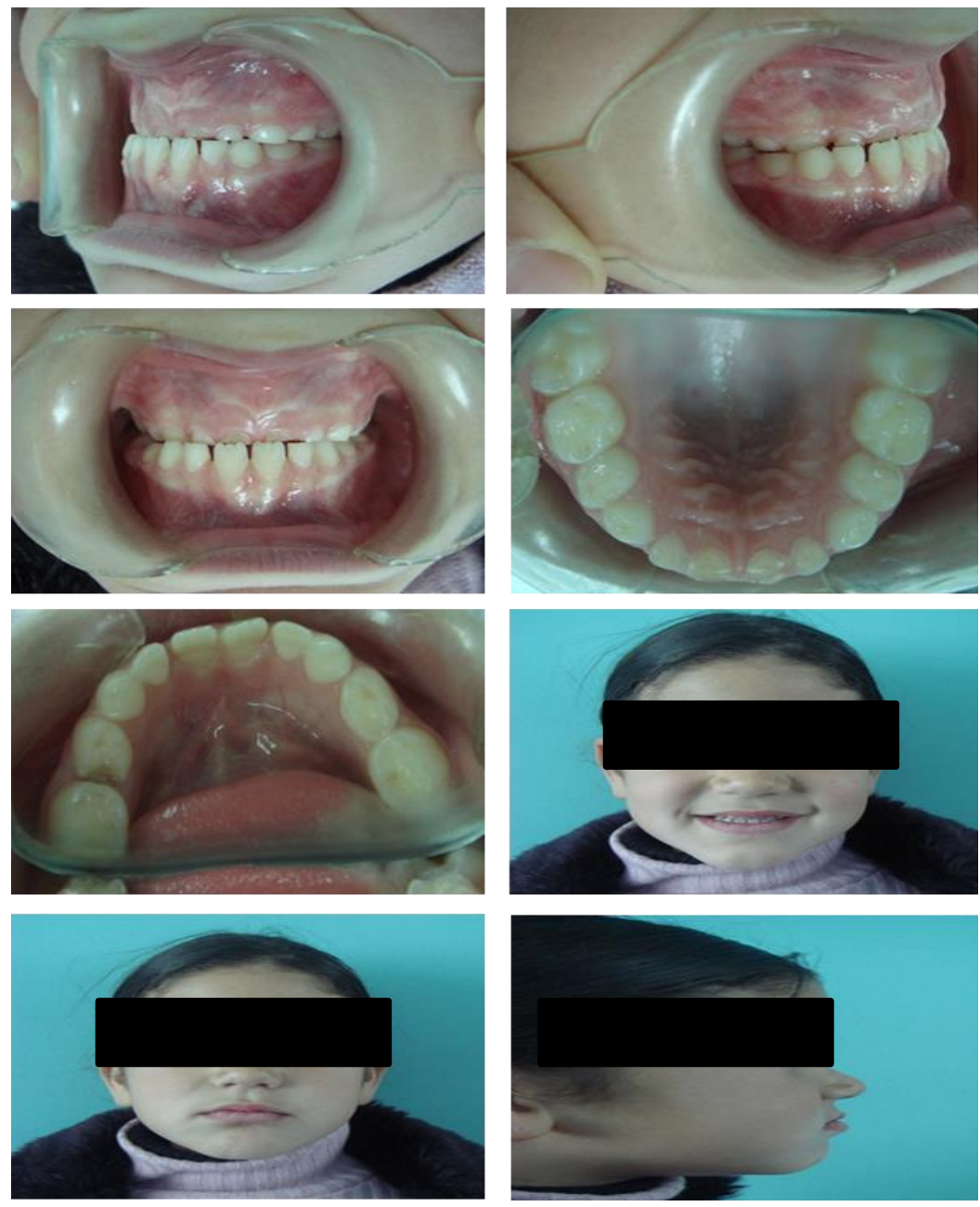

Figure 1a Intraoral and extraoral photographs of case-1 
Clinical examination revealed that the patient was at the early mixed-dentition stage, with erupting maxillary and mandibular permanent first molars and mandibular permanent central incisors. Beside the anterior cross bite there was a mesial step relation between maxillary and mandibular primary second molars on both the right and left sides, while the right canine was in CLI and the left primary canine showed Class III relation. The lower midline was 2 mm deviated to the right (Fig. 1a). No occlusal interferences, mandibular deviation, mouth-opening limitation or any other clinical sign indicating temporomandibular dysfunction was noticed during intraoral clinical examination. Good oral hygiene was observed, no gingival inflammation was present, only one caries in 84 tooth was observed. The incisal faces of all anterior maxillary primary teeth were badly worn. Worn occlusal facets in teeth $53,54.63,64,74,73,72,82,83$ and 84 were also present (Fig. 1a). The child had no history of pain, even with mechanical stimulation. Radiographic examination confirmed pronounced wear in the above-mentioned primary teeth. No damage to supporting tissues was verified (Fig. 1b).
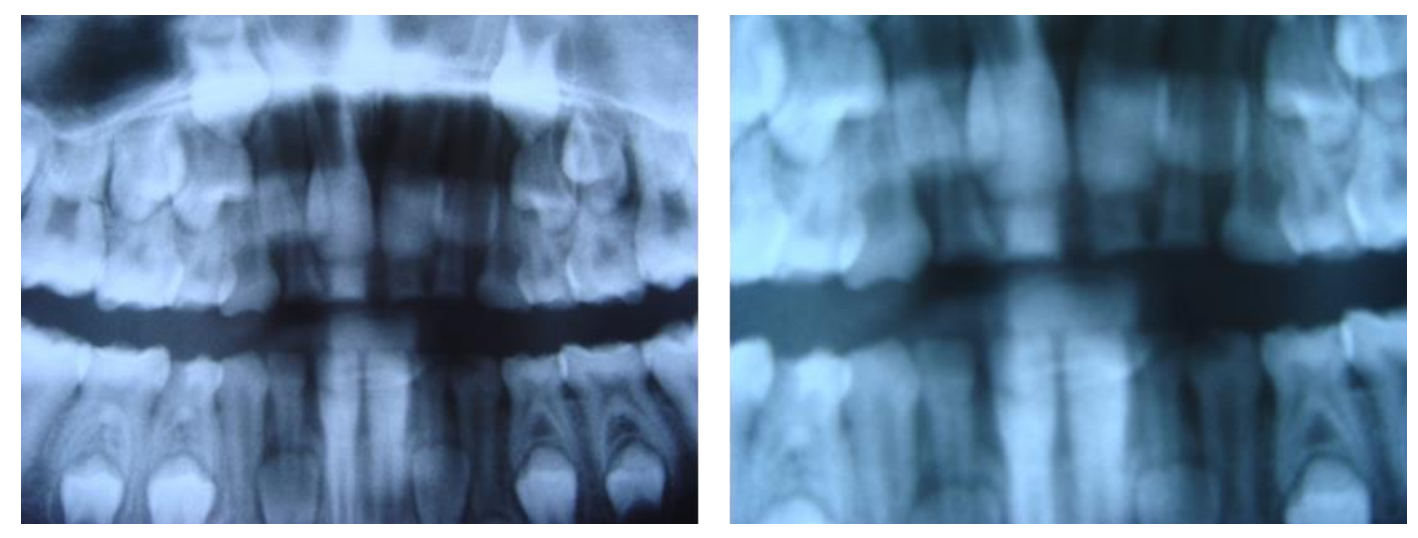

Figure 1b Radiographic x-rays of the case-1

The treatment plan for this patient consisted of three parts: composite resin restoration in tooth 84; placement of a softbased biteplate, $3 \mathrm{~mm}$ thick, on the mandibular arch for night use; and referral for psychological monitoring. Follow-up visits were scheduled every seven weeks to verify tooth wear and monitor eruption of permanent teeth and bone growth. When necessary, splints were modified to allow adequate bone growth and tooth eruption. The patient was followed up for one year.

\subsection{Case 2}

A 6-year-old girl was brought to the orthodontic clinic by her parents. According to her mother, the child usually clenched her teeth throughout the day and gnashed and clenched them during sleep. The mother stated that the child suffered of hypoxia during labour and due to that the she has a kind of cerebral palsy and mental retardation, but she does not use any medication for that. Also they mentioned that she is often abused by the other children in the family and neighbourhood. Her mother reported that the bruxism had started 2 years earlier, and that she has no other medical problem. During consultation, the patient was very hyperactive, and we faced some problems in taking the $\mathrm{x}$ rays and photographs. Her medical history was uneventful and evaluation of her diet revealed no ingestion of acid drinks or medication. Intraoral clinical examination showed that the patient was in the early mixed-dentition stage. The relation between maxillary and mandibular permanent first molars was Angle Class I on both right and left sides; a Class I relation was also observed between maxillary and mandibular primary canines bilaterally. Neither mouth-opening limitation nor crepitation was detected during the examination of the temporomandibular joint. The patient did not present any functional mandibular deviation, but she has $1 \mathrm{~mm}$ midline shift (Fig. 2a).Maxillary and mandibular permanent first molars and mandibular permanent central incisors were already in the arches. Furthermore, fair oral hygiene was observed; probing revealed no gingival bleeding. The patient presented caries in teeth 54, 64, 65 and 84 . The tooth 75 was extracted and remaining roots of tooth85 were present. Pronounced wear was observed in all primary teeth (Fig. 2a).

The child did not report a history of pain in either worn teeth or the temporomandibular joint. Radiographic examination confirmed pronounced wear on primary teeth and the absence of injury to supporting tissues.( Fg.2b)The treatment plan for this patient included conservative treatment for the carouse teeth, placement of a soft-based biteplate, $3 \mathrm{~mm}$ thick, on the mandibular arch, which will act as space maintainer also, for day and night use and referral for psychological monitoring. Follow-up visits were scheduled every seven weeks to verify tooth wear and monitor eruption of permanent teeth and bone growth. When necessary, splints were modified to allow adequate bone growth. The patient was followed up for one year. 

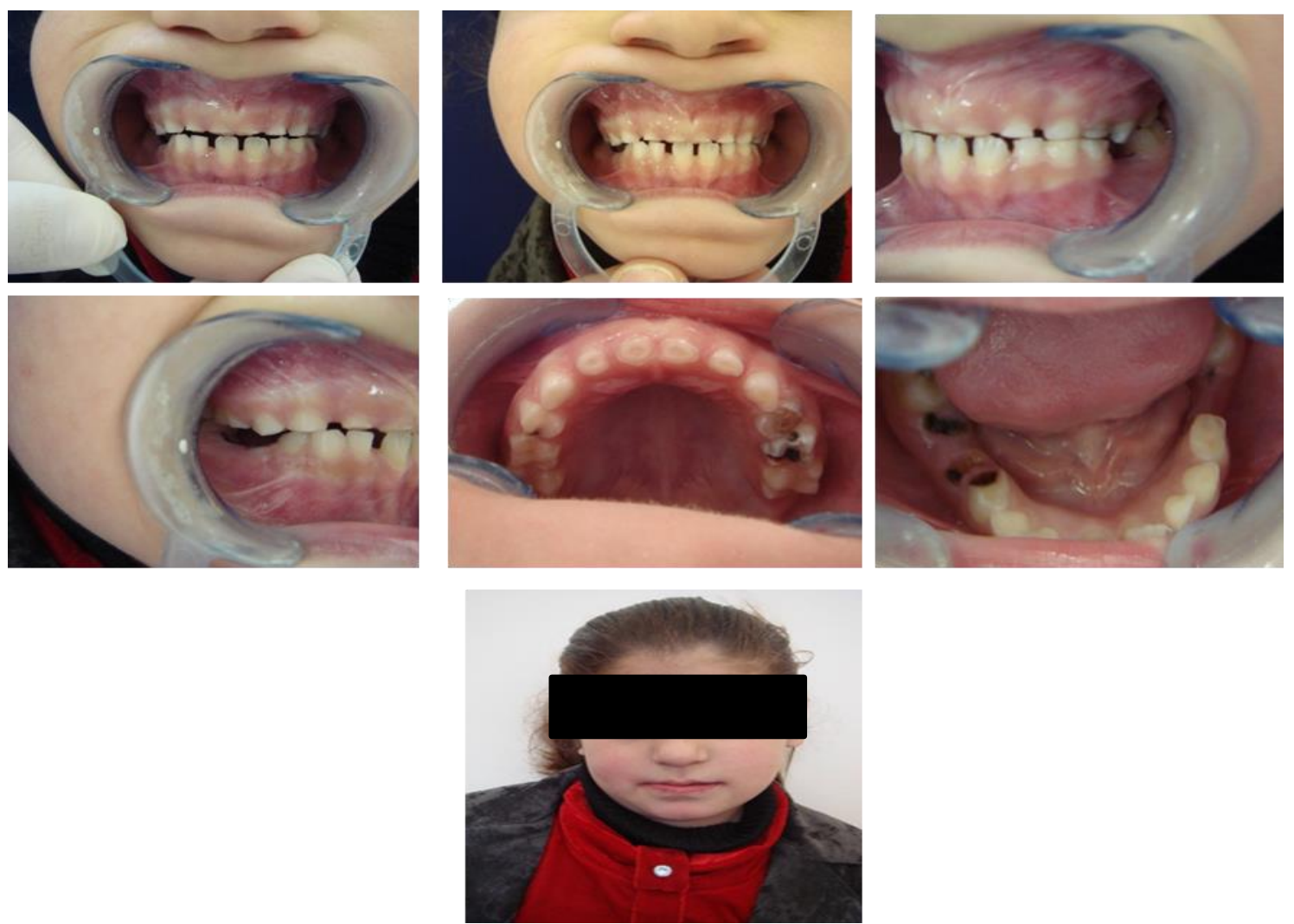

Figure 2a Intraoral and extraoral photographs of case-2
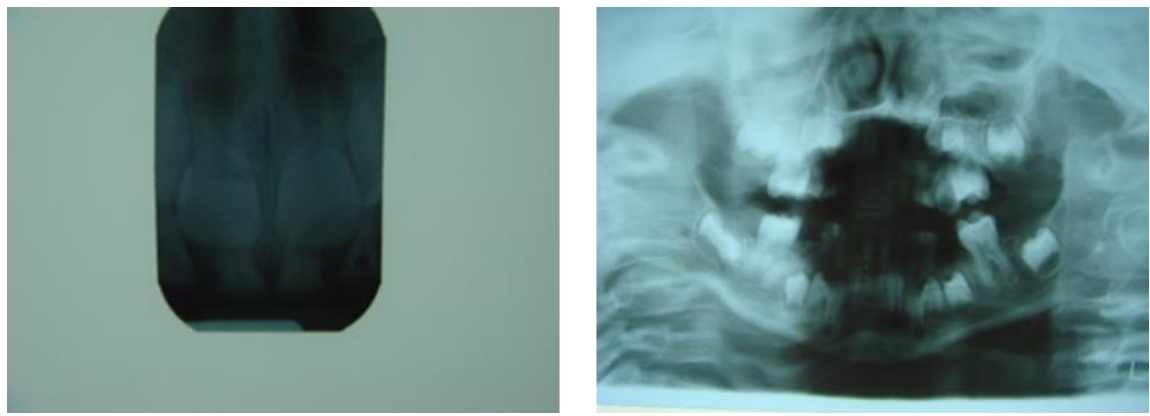

Figure $2 \mathbf{b} \mathrm{X}$ ray radiographs of case- 2

\subsection{Case 3}

This case severity is less than the previous two cases. A 5-year-old boy was brought to our orthodontic clinic by his father. According to his father, the child usually gnashed and clenched his teeth during sleep. The father reported that the bruxism had started one year earlier. During consultation, the patient was very calm and shy. His medical history was uneventful and evaluation of hir diet revealed no ingestion of acid drinks or medication. During the investigation and with the help of the social worker at his kindergarten we realised that the boy is often beaten by his 1.5 years younger sister. Intraoral clinical examination showed that the patient was in the early mixed-dentition stage. The maxillary and mandibular permanent first molars were not erupted yet; a Class I relation was also observed between maxillary and mandibular primary molars and canines bilaterally. Neither mouth-opening limitation nor crepitation was detected during the examination of the temporomandibular joint. The patient did not present any functional mandibular deviation, (Fig. 3a). Mandibular permanent central incisors were already in the arch. Furthermore, good oral hygiene was observed; probing revealed no gingival bleeding. The patient presented no caries in any of the teeth. (Fig. 3a). Wearing facets were observed in the upper and lower deciduous molars and canines. The child did not report 
a history of pain in either worn teeth or the temporom andibular joint. Radiographic examination confirmed pronounced wear on primary molars and canines and the absence of injury to supporting tissues.(Fig.3b)

The treatment plan for this patient was to place a soft-based biteplate, $3 \mathrm{~mm}$ thick, on the mandibular arch for night use and referral for psychological monitoring. Follow-up visits were scheduled every seven weeks to verify tooth wear and monitor eruption of permanent teeth and bone growth. When necessary, splints were modified to allow adequate bone growth. The patient was followed up for one years every seven weeks and then he was monitored once a year for 3 years. (Fig.3c)
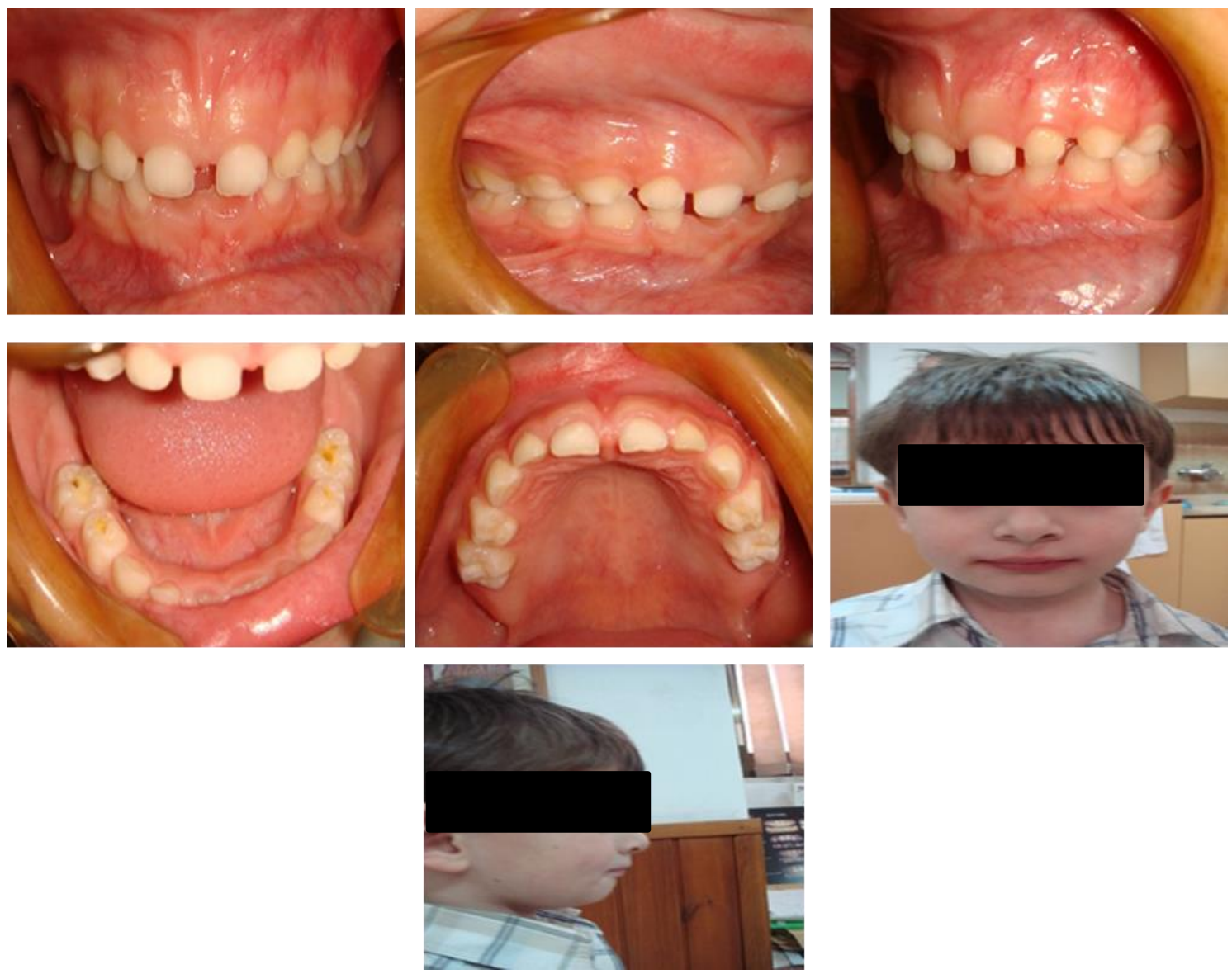

Figure 3a Extraoral and intraoral photographs of case no.3 at the beginning of the treatment.
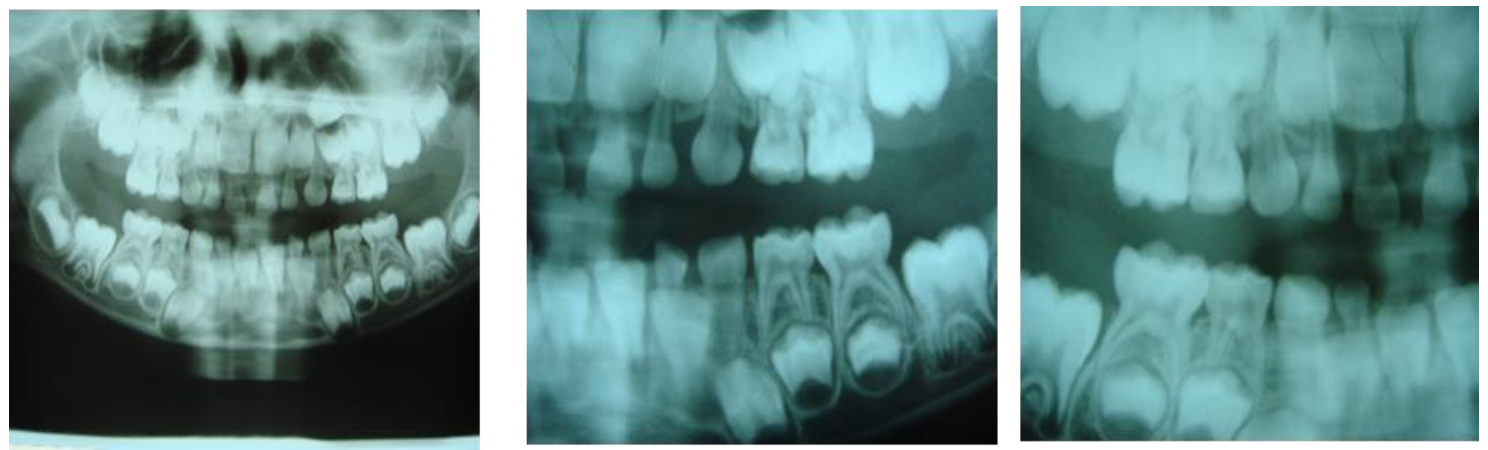

Figure 3b Xray radiographs of case no.3 

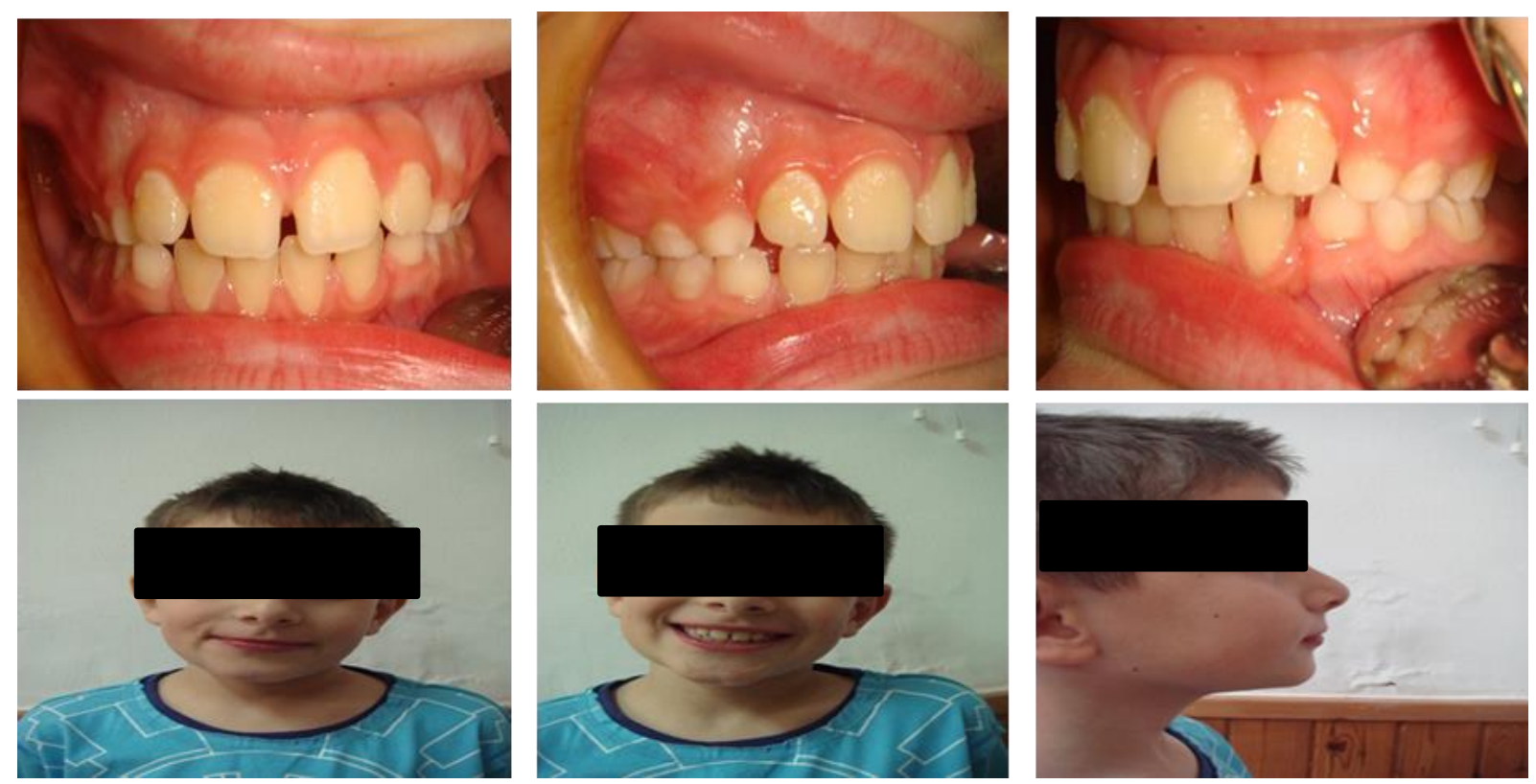

Figure 3c Intraoral and extraoral photographs of case no.3 after 3 years of treatment

All the biteplates in three cases were fully renewed every six months. In all cases, Bruxism has disappeared in the first six months after using the bite plate.

\section{Discussion}

The etiology of bruxism is complex and multifactorial demanding systemic, psychological, occupational, and genetic factors. Recurrent provocation during sleep, which is associated with increased anxiety and stress, is regarded as the main cause of poor sleep quality $[1,7,10,49,50]$. These variables influence the release of chemical mediators, which provoke catecholamine release, altering the initiation and maintenance of wakefulness and sleep [51]. Children with bruxism may have additional symptoms, such as temporomandibular disorders, presence of tooth wear facets, [52] headaches, earaches, and pain in the masticatory muscles [53]. According to Carra et al., [54] Bruxism in young children can also be associated with fatigue of the masticatory musculature, headaches, and noisy breathing during sleep [55, 56, $57,58]$. Bruxism is a result of stress and anxiety in children. [56] Our report focused on 3 children with severe wear of primary teeth caused by gnashing. In the three cases, the condition was believed to have been triggered by psychological disturbances, resulting from harrowing and abusement although they had different experiences. Furthermore, all of them had been influenced by certain local factors, also different for each patient. Funch and Gale [59] stated that bruxism is correlated with psychological factors, suggesting that the kind of life the patient leads exerts great influence on the frequency, duration and severity of the condition. Thus, based on the presence of the emotional problems reported by the parents, we believed that in all probability the condition presented by these patients was bruxism.

Taking diet and the absence of medical history of reflux in the patients into account, the possibility of the observed dental wear arising from a chemical process was discarded in accordance with Imfeld[60] and Lussi et al., [61] who have stated that the etiological factors contributing to chemical dissolution of dental enamel in children are related to either acid diet or medication.

The prevalence of bruxism in children is estimated to range from $7 \%$ to $15.1 \% .3-5 \mathrm{~A}$ few studies confirm a higher rate in females than males [7, 62]. However, as bruxism is a condition related to certain personality characteristics aggression, anxiety and hyperactivity mainly triggered by life events, [26] significant differences between sexes are unlikely [63].

Some authors describe bruxism as a condition of multifactorial etiology, determined by an association of psychological, local and systemic factors $[3,64]$. Local factors include occlusal interferences, malocclusion and temporomandibular dysfunction. [65] Allergic diseases represent systemic factors [66]. For the first case who has experienced social separation anxiety Rostami et al., [67] stated that the preschoolers in the High-Increasing separation anxiety trajectory had almost double the risk of presenting sleep bruxism For the second case she had a kind of cerebral palsy and mental retardation. Sandes et.al [68] and Peres et al., [69] stated that the more common oral conditions in individuals with CP 
include higher mean decayed, missing and filled surfaces index, higher plaque index, tendency for delayed eruption of permanent molars, malocclusion, as well as high rates of bruxism. But the patient was a simple CPcase and she did not use any medications for that but she was often abused by the children in the family and neighborhood. Our third case he was often abused by his little sister, and he did not have any medical problems. we believe that the reason of the bruxism in these three cases are related to psychological problems due to the level of emotional stress generated by life events experienced by the patients.

A study by Restrepo et al., [12] demonstrated that several psychological techniques have been efficacious in reducing signs of bruxism when they were applied to 33 children aged 3-6. Thus, an important part of treatment of these three cases was psychology treatment sessions. The second part of the treatment was Soft-based tailor-made bite plates were prescribed for the three children. According to Hachmann et al., [70] and McDonald et al., [65] a bite-plate covering the occlusal surfaces of all teeth should be used by patients suffering from bruxism to prevent continuous abrasion. According to. Casamassimo et al., [71] the use of a myorelaxing plate is indicated and constitutes the initial phase of the therapy. Solberg et,al. [72] assert that the use of biteplates reduces muscular activity, thus giving more comfort to the patient. The sameresults were achieved in the review article of Chisini LA et al., [73]. A soft-based material was chosen to protect the primary teeth, as suggested by Casamassimo et al., [71]. Furthermore, the thickness (3 mm) was sufficient to prevent perforation and increase resistance to impact. McDonald et.al [65] recommended that the bite plate should be 2-3 mm thick and extend to the vestibular area. The plates that we used are removable and the patients used them mainly at nighttime, and to allow a normal growth of the lower jaws and to permit the permanent teeth to erupt they were modified at the appointments and al the plates were renewed completely every six months.

There is also evidence that, in younger children, bruxism may be a consequence of the immaturity of the masticatory neuromuscular system, Vanderas et al., [74] have demonstrated that stress and anxiety may be directly related to bruxism, as patients suffering from bruxism show a higher catecholamine level, generally ascribed toemotional stress. Nevertheless, no catecholamine measurement of any type was performed on the patients in this article.

According to Lobbezoo and Naeije [14] level of stress and personality type have been included in the etiology of bruxism for many years. However, the exact contribution of psychological factorsremains debatable. A controlled questionnaire study [75] demonstrated that those with bruxism generally present emotional imbalance and tend to develop more psychosomatic disorders. Kampe and others [76] have confirmed these findings who also demonstrated the presence of a higher level of anxiety in a group of people with bruxism. All these findings support our theory that our presented three case had bruxism related to psychological problems or events.

\section{Conclusion}

In modern society bruxism is becoming an increasingly common condition in children. In treating this parafunctional habit, dentists, mainly orthodontist and paedodontists play a leading role in determining possible etiological factors to warn parents and to lead its Multidisciplinary treatment. This article will help dentists in general to handle and manage the treatment of children with bruxism.

\section{Compliance with ethical standards}

\section{Disclosure of conflict of interest}

All the authors declare that they do not have any conflict of interest or any financial interest in this article.

\section{Statement of informed consent}

Informed consent was obtained from all individual participants included in the study.

\section{References}

[1] Antonio AG, Pierro VS and Maia LC. (2006). Bruxism in Children: A Warning Sign for Psychological Problems J Can Dent Assoc, 72(2), 155-60.

[2] Pingitore G, Chrobak V and Petrie J. (1991).The social and psychologic factors of bruxism. J Prosthet Dent, 65(3), 443-6.

[3] Attanasio R. (1991). Nocturnal bruxism and its clinical management. Dent Clin North Am, 35(1), $245-52$. 
[4] Nilner M. (1981). Prevalence of functional disturbances and diseases of the stomatognathic system in 15-18 year olds. Swed Dent J, 5(5-6), 189-97.

[5] Nilner M and Kopp S. (1983). Distribution by age and sex of functional diseases of the stomatognathic system in 7-18 year olds. Swed Dent J, 7(5), 191-8.

[6] Laberge L, Tremblay RE, Vitaro F and Montplaisir J. (2000). Development of parasomnias from childhood to early adolescence. Pediatrics, 106(1 Pt 1), 67-74.

[7] Bayardo RE, Mejia JJ, Orozco S and Montoya K. (1996). Etiology of oral habits. ASDC J Dent Child, 63(5), 350-3.

[8] Vanderas AP and Manetas KJ. (1995). Relationship between malocclusion and bruxism in children and adolescents: a review. Pediatr Dent, 17(1), 7-12.

[9] Lobbezoo F and Naeije M. (2001). Bruxism is mainly regulated centrally, not peripherally. J Oral Rehabil, 28(12), 1085-91.

[10] Monaco A, Ciammella NM, Marci MC, Pirro R and Giannoni M. (2002). The anxiety in bruxer child. A case-control study. Minerva Stomatol, 51(6), 247-50.

[11] Gunnar E, Egermark I and Magnnuson T. (2003). Predictors of bruxism,other oral parafunctions, and tooth wear over a 20-year follow up period. J Orofac Pain, 17, 50-57.

[12] Restrepo CC, Alvarez E, Jaramillo C, Velez C and Valencia I. (2001). Effects of psychological techniques on bruxism in childrenwith primary teeth. J Oral Rehabil, 28, 354-360.

[13] Negoro T, Briggs J, Plesh O, Nielsen I, McNeill C and Miller AJ. (1998). Bruxing patterns in children compared to intercuspalclenching and chewing as assessed with dental models,electromyography and incisor jaw tracing: preliminarystudy. ASDC J Dent Child, 65, 449-458.

[14] Lobbezzo F and Naeije M. (2001). Bruxism is mainly regulated centrally,not peripherally. J Oral Rehabil, 28, 10851091.

[15] Castelo PM, Gaviao MB, Pereira LJ and Bonjardim LR. (2005). Relationshipbetween oral parafunctional/nutritive suckinghabits and temporomandibular joint dysfunction in primarydentition. Int J Paediatr Dent, 15, 29-36.

[16] Camparis CM and Siqueira JT. (2006). Sleep bruxism: clinical aspectsand characteristics in patients with and without chronic orofacial pain. Oral Surg Oral Med Oral Pathol Oral RadiolEndod, 101, 188-193.

[17] Bonjardim LR, Gaviao MB, Pereira LJ, Castelo PM and Garcia RC. (2005). Signs and symptoms of temporomandibular disorders in adolescents. Pesqui Odontol Bras, 19, 93-98.

[18] Magnusson T, Egermarki I and Carlsson GE. (2005). A prospectiveinvestigation over two decades on signs and symptoms oftemporomandibular disorders and associated variables. A final summary. Acta Odontol Scand, 63, 99-109.

[19] Molina OF, dos Santos J, Mazzetto M, Nelson S, Nowlin T and Mainieri ET. (2001). Oral jaw behaviors in TMD and bruxism: a comparison study by severity of bruxism. Cranio, 19, 114-122.

[20] Demir A, Uysal T, Guray E and Basciftci FA. (2004). The relationshipbetween bruxism and occlusal factors among seven- to19-year-old Turkish children. Angle Orthod, 74, 672-676.

[21] Sari S and Sonmez H. (2001). The relationship between occlusal factors and bruxism in permanent and mixed dentition inTurkish children. J Clin Pediatr Dent, 25, 191-194.

[22] Oksenberg A and Arons E. (2002). Sleep bruxism related to obstructivesleep apnea: The effect of continuous positive airway pressure. Sleep Med, 3, 513-515.

[23] Lavigne G and Palla S. (2010). Transient morning headache: recognizingthe role of sleep bruxism and sleepdisordered breathing.J Am Dent Assoc, 141, 297-299.

[24] Manfredini D, Landi N, Fantoni F, Segù M and Bosco M. (2005). Anxiety symptoms in clinically diagnosed bruxers. J Oral Rehabil, 32, 584-588.

[25] Tsai CM, Chou SL,Gale EN and Mccall JR. (2002). Human masticatory muscle activity and jaw position under experimental stress. J Oral Rehabil, 29, 44-51.

[26] Giraki M, Schneider C, Schäfer R, Singh P, Franz M, Raab WH and Ommerborn MA. (2010). Correlation between stress, stresscoping and current sleep bruxism. Head Face Med, 6, 2. 
[27] Bayardo RE, Mejia JJ, Orozco S and Montoya K. (1996). Etiology of oral habits. ASDC J Dent Child, 63, 350 353.

[28] Lobbezoo F, Soucy JP, Montplaisir JY and Lavigne GJ. (1996). Striatal d2 receptor binding in sleep Bruxism: A controlled study with iodine-123-iodobenzamide and single-photon-emission computed tomography. J Dent Res, 75, 1804-1810.

[29] Lobbezoo F, Soucy JP, Hartman NG, Montplaisir JY and Lavigne GJ. (1997). Effects of the d2 receptor agonist bromocriptine on sleep bruxism of two single-patient clinical trials. J Dent Res, 76, 1610-1614.

[30] Seraidarian P, Seraidarian PI, das Neves Cavalcanti B, Marchini L and Claro Neves AC. (2009). Urinary levels of catecholaminesamong individuals with and without sleep bruxism. Sleep Breath, 13, 85-88.

[31] Hirsch C, John MT, Lobbezoo F, Setz JM and Schaller HG. (2004). Incisal tooth wear and self-reported TMD pain in children and adolescents. Int J Prosthodont, 17, 205-210.

[32] Farsi NM. (2003). Symptoms and signs of temporomandibular disorders and oral parafunctions among Saudi children. J Oral Rehabil, 30, 1200-1208.

[33] Carlsson GE, Egermark I and Magnusson T. (2002). Predictors of signs and symptoms of temporomandibular disorders: a 20-year follow-up study from childhood to adulthood. Acta Odontol Scand, 60, 180-185.

[34] Manfredini D, Landi N, Bandettini Di Poggio A, Dell'Osso L and Bosco M. (2003). A critical review on the importance of psychological factors in temporomandibular disorders. Minerva Stomatol, 52, 321-330.

[35] Michelotti A, Martina R, Russo M and Romeo R. (1998). Personality characteristics of temporomandibular disorder patientsusing M.M.P.I. Cranio, 16, 119-125.

[36] Restrepo CC, Medina I and Patiño I. (2011). Effect of occlusal splints onthe temporomandibular disorders, dental wear and anxiety of bruxist children. Eur J Dent, 5(4), 441-50.

[37] Bahman Seraj et al.,(2010). The Prevalence of Bruxism and Correlated Factors in Children Referred to Dental Schools of Tehran, Based on Parents' ReportIranian Journal of Pediatrics, 20(2), 174180.

[38] Hirsch C, Hoffmann J and Türp JC. (2012). Are temporomandibular disorder symptoms and diagnoses associated with pubertal development in adolescents? An epidemiological study. J Orofac Orthop, 73, 6-8, 10-18.

[39] Vélez AL, Restrepo CC, Peláez-Vargas A, et al.,(2007). Head posture and dental wear evaluation of bruxist children with primary teeth. J Oral Rehabil, 34, 663-670.

[40] De la hoz-aizpurua JL, Diaz-alonso E, Latouche-arbizu R and Mesa-jimenez J. (2011). Sleep bruxism. Conceptual review and update. Med Oral Patol Oral Cir Bucal, 16, e231-238.

[41] Macedo CR, Silva AB, Machado MA, Saconato H and Prado GF. (2007). Occlusal splints for treating sleep bruxism bruxism (tooth grinding). Cochrane Database Syst Rev, (4), CD005514.

[42] Huynh N, Lavigne GJ, Lanfranchi PA, Montplaisir JY and De champlain J. (2006). The effect of 2 sympatholytic medications--propranolol and clonidine-on sleep bruxism: experimental randomized controlled studies. Sleep, 29, 307-316.

[43] Tan EK and Jankovic J. (2000). Treating severe bruxism with botulinum toxin. J Am Dent Assoc, 131, $211-216$.

[44] Monroy PG and Da fonseca MA. (2006). The use of botulinum toxin-a in the treatment of severe bruxism in a patient with autism: a case report. Spec Care Dentist, 26, 37-39.

[45] Lavigne GJ, Soucy JP, Lobbezoo F, Manzini C, Blanchet PJ and Montplaisir JY. (2001). Double-blind, crossover, placebo-controlled trial of bromocriptine in patients with sleep bruxism. Clin Neuropharmacol, 24, 145-149.

[46] Saletu A, Parapatics S, Saletu B, Anderer P, Prause W, Putz H, Adelbauer J and Saletu-zyhlarz GM. (2005). On the pharmacotherapy of sleep bruxism: placebo-controlled polysomnographic and psychometric studies with clonazepam. Neuropsychobiology, 51, 214-225.

[47] Saletu A, Parapatics S, Anderer P, Matejka M and Saletu B. (2010). Controlled clinical, polysomnographic and psychometric studies on differences between sleep bruxers and controls and acute effects of clonazepam as compared with placebo. Eur Arch Psy Clin Neurosci, 260, 163-174.

[48] Tatiana Helena Junqueira et al.,(2013). (Association of infantile bruxism and the terminal relationships of the primary second molars. Braz Oral Res., (São Paulo), 27(1), 42-7.

[49] Ahlberg J, Lobbezoo F, Ahlberg K, Manfredini D, Hublin C, Sinisalo J, et al.,(2013). Self-reported bruxism mirrors anxiety and stress in adults. Med Oral Patol Oral Cir Bucal, 18, e7-11. 
[50] Sruthi Suguna and Deepa Gurunathan. (2020). Quality of life of children with sleep bruxism. J Family Med Prim Care, 9(1), 332-336.

[51] Carra MC, Huynh N and Lavigne G. (2012). Sleep bruxism: A comprehensive overview for the dental clinician interested in sleep medicine. Dent Clin North Am, 56, 387-413.

[52] Serra-Negra JN, Ramos-Jorge ML, Flores-Mendoza CE, Paiva SM and Pordeus IA. (2009). Infulence of psychosocial factors on the development of sleep bruxism among children. Int J Paediatr Dent, 19, 309-17.

[53] Pizolato RA, Gaviao MB, Berretin-Felix G, Sampaio AC and Trindade Junior AS. (2007). Maximal bite force in young adults with temporomandibular disorders and bruxism. Braz Oral Res, 21, 278-83.

[54] Carra MC, Huynh N, Morton P, Rompré PH, Papadakis A, Remise C, et al.,(2011). Prevalence and risk factors of sleep bruxism and wake-time tooth clenching in a 7-17 yr old population. Eur J Oral Sci, 119,386-94.

[55] Pizzol KE, Carvalho JC, Konish F, Marcomini EMS and Giusti JSM. (2006). Bruxismo na infancia: Factors etiologicos e possiveis tratamentos. Rev Odontol UNESP, 35, 157-63.

[56] Manfredini D and Lobbezoo F. (2009). Role of psychological factors in the etiology of bruxism. J Orofac Pain, 23, $153-66$.

[57] Michelotti A, Cioffi I, Festa P, Scala G and Farella M. (2010). Oral Parafunctions as risk factors for diagnostic TMD subgroups. J Oral Rehabil, 37, 157-62.

[58] Muna A and Ahmad R. (2014). Assessment of the Prevalence of Dental Anxiety among Palestinian Clients Attending Dental Clinics in Bethlehem City: Cross Sectional Study. Psychology and Behavioral Sciences, 3(6), 197202.

[59] Funch DP and Gale EN. (1980). Factors associated with nocturnal bruxism and its treatment. J Behav Med, 3(4), 385-7.

[60] Imfeld T. (1996). Dental erosion. Definition, classification and links. Eur J Oral Sci, 104(2 Pt 2), 151-5.

[61] Lussi A, Kohler N, Zero D, Schaffner M and Megert B. (2000). A comparison of the erosive potential of different beverages in primary and permanent teeth using an in vitro model. Eur J Oral Sci, 108(2), 110-4.

[62] Gorayeb MA and Gorayeb R. (2002). Association between headache and anxiety disorders indicators in a school sample from Ribeirao Preto, Brazil]. Arq Neuropsiquiatr, 60(3-B), 764-8.

[63] Vanderas AP and Papagiannoulis L. (2002). Multifactorial analysis of the aetiology of craniomandibular dysfunction in children. Int J Paediatr Dent, 12(5), 336-46.

[64] Okeson JP. (1989)Temporomandibular disorders in children. Pediatr Dent, 11(4), 325-9.

[65] McDonald RE, Hennon DK and Avery DR. (2000). Diagnosis and correction of minor irregularities in the developing dentition. In: McDonald RE, Avery DR, Dean JA, editors. Pediatric dentistry for the child and adolescent. 7th ed. Chicago: Mosby, 487.

[66] Casamassimo P. (1994). Periodontal considerations. In: Pinkham J, Casamassimo OS, Fields HW, McTigue DJ, Nowak A, editors. Pediatric dentistry — infancy through adolescence. 2nd ed. Philadelphia: WB Saunders Co., 372.

[67] Garmroudinezhad Rostami E, Touchette É, Huynh N, Montplaisir J, Tremblay RE, Battaglia M, Boivin M. (2020). High separation anxiety trajectory in early childhood is a risk factor for sleep bruxism at age 7. Sleep, 43(7), zsz317.

[68] MT dos Santos, D Masiero and MR Simionato. (2002). Risk factors for dental caries in children with cerebral palsy, Special Care in Dentistry, 22(3), 103-107.

[69] ACD Peres, MO Ribeiro, Y Juliano, MF C'esar and RCA Santos. (2007). Occurrence of bruxism in a sample of Brazilian children with cerebral palsy, Special Care in Dentistry, 27(2), 73-76.

[70] Hachmann A, Martins EA, Araujo FB and Nunes R. (1999). Efficacy of the nocturnal biteplate in the control of bruxism for 3 to 5 year old children. J Clin Pediatr Dent, 24(1), 9-15.

[71] Solberg WK, Clark GT and Rugh JD. (1975). Nocturnal electromyographic evaluation of bruxism patients undergoing short term splint therapy. J Oral Rehabil, 2(3), 215-23. 
[72] Chisini LA, San Martin AS, Cademartori MG, Boscato N, Correa MB and Goettems ML. (2020). Interventions to reduce bruxism in children and adolescents: a systematic scoping review and critical reflection. Eur J Pediatr, $179(2), 177-189$.

[73] Vanderas AP, Menenakou M, Kouimtzis TH and Papagiannoulis L. (1999). Urinary catecholamine levels and bruxism in children. J Oral Rehabil, 26(2), 103-10.

[74] Olkinuora M. (1972). Psychosocial aspects in a series of bruxists compared with a group of non-bruxists. Proc Finn Dent Soc, 68(4), 200-8.

[75] Kampe T, Edman G, Bader G, Tagdae T and Karlsson S. (1997). Personality traits in a group of subjects with longstanding bruxing behaviour. J Oral Rehabil, 24(8), 588-93.

\section{How to cite this article}

Rahhal A, Ahmead M, Jaradat M and Issa H. (2020). Bruxism in children, is it a result of psychological problems? World Journal of Advanced Research and Reviews, 7(1), 234-244. 